\title{
Baseline tumour necrosis factor alpha levels predict the necessity for dose escalation of infliximab therapy in patients with rheumatoid arthritis
}

\author{
Tsutomu Takeuchi, ${ }^{1}$ Nobuyuki Miyasaka, ${ }^{2}$ Yoshihiko Tatsuki, ${ }^{3}$ Toshiro Yano, ${ }^{3}$ \\ Toru Yoshinari, ${ }^{3}$ Tohru Abe, ${ }^{4}$ Takao Koike ${ }^{5}$
}

- Supplementary figures and tables are published online only. To view these files please visit the journal online at (http://ard. bmj.com).

${ }^{1}$ Division of Rheumatology, Department of Internal Medicine, School of Medicine, Keio University, Shinjuku-ku, Tokyo, Japan

2Department of Medicine and Rheumatology, Graduate School of Tokyo Medical and Dental University, Bunkyo-ku, Tokyo, Japan

${ }^{3}$ Mitsubishi Tanabe Pharma Corporation, Osaka, Japan ${ }^{4}$ Saitama Medical Center, Saitama Medical University, Kawagoe, Japan

${ }^{5}$ Department of Medicine II, Hokkaido University Graduate School of Medicine, Sapporo, Japan

\section{Correspondence to}

Tsutomu Takeuchi, Division of Rheumatology, Department of Internal Medicine, School of Medicine, Keio University, 35 Shinanomachi, Shinjuku-ku, Tokyo 160-8582, Japan; tsutake@z5.keio.jp

Accepted 4 March 2011 Published Online First 8 April 2011

\begin{abstract}
Objectives To investigate the possible role of baseline plasma tumour necrosis factor alpha levels (baseline-TNF) on the clinical response to infliximab in patients with rheumatoid arthritis (RA).

Methods Patients with RA refractory to methotrexate received 3,6 , or $10 \mathrm{mg} / \mathrm{kg}$ of infliximab every 8 weeks, in a randomised, double-blind manner: the RISING study. Clinical response (disease activity score in 28 joints based on C-reactive protein or American College of Rheumatology core set) at week 54 and serum infliximab levels were compared in three patient groups with low, intermediate, or high baseline-TNF (TNF-Iow, TNF-int, or TNF-high)
\end{abstract}

Results In TNF-low patients, the clinical response to different doses of infliximab was comparable, whereas TNF-int patients exhibited a dose-dependent trend. In contrast, TNF-high patients (approximately 13\% of the total patients) had a clinical response to $10 \mathrm{mg} / \mathrm{kg}$ significantly better than the response to 3 and $6 \mathrm{mg} / \mathrm{kg}$ of infliximab. In TNF-high patients, the median trough serum levels of infliximab were below the detection limit $1<0.1$ $\mu \mathrm{g} / \mathrm{ml}$ ) at 3 and $6 \mathrm{mg} / \mathrm{kg}$ but were greater than $2 \mu \mathrm{g} /$ $\mathrm{ml}$ at $10 \mathrm{mg} / \mathrm{kg}$, whereas the levels were approximately $1 \mu \mathrm{g} / \mathrm{ml}$ for each dosage group in TNF-low patients. Conclusion In patients with RA, baseline-TNF is significantly associated with the clinical response to infliximab in patients with a high baseline-TNF. A higher dose of infliximab may be necessary in these patients, whereas lower doses of infliximab are sufficient for those with a low baseline-TNF. Baseline-TNF may be a useful measure for personalising the treatment of RA using infliximab.

Rheumatoid arthritis (RA) is a chronic, systemic inflammatory disease that results in joint destruction and disability. ${ }^{1}$ Levels of tumour necrosis factor alpha (TNF), an inflammatory cytokine, are elevated in the blood and synovial fluid of patients with RA, and may play a central role in its pathogenesis. ${ }^{2-7}$

Although infliximab, an anti-TNF antibody, exhibits excellent effectiveness in RA, ${ }^{8-11}$ insufficient response to the standard treatment of infliximab ( $3 \mathrm{mg} / \mathrm{kg}$ per 8 weeks) has also been observed in some cases in clinical practice. Such patients are usually treated by dose escalation or by shortening the dose interval of the infliximab therapy. ${ }^{12-15}$

The RISING study (NCT00691028) is a randomised, double-blind clinical trial, which has shown that the clinical response to infliximab at a dose of $10 \mathrm{mg} / \mathrm{kg}$ is significantly higher than the response to $3 \mathrm{mg} / \mathrm{kg}$ infliximab, and that a trough serum level of $1 \mu \mathrm{g} / \mathrm{ml}$ is the threshold for clinical response. ${ }^{16}$ However, clinical response to different dose levels of infliximab was significant only for American College of Rheumatology (ACR) improvement criteria and the European League Against Rheumatism (EULAR) responses, and the measurable difference was small.

Several clinical studies have attempted to address whether a higher dose of infliximab provides a better clinical response than standard doses in patients with RA. ${ }^{8-11} 17$ However, the results were not consistent among those studies. In addition, a randomised, double-blind study comparing dose escalation and continuation of the standard dose in patients with RA who had an insufficient response to $3 \mathrm{mg} / \mathrm{kg}$ of infliximab clearly demonstrated no beneficial response by dose escalation, ${ }^{18}$ contrary to our results.

Although the standard dose of infliximab can be efficacious in a large proportion of patients with $\mathrm{RA}$, some patients may require a higher dose of infliximab to achieve clinical response. ${ }^{19} 20$ The inconsistent results mentioned above might be explained by the different proportion of patients who might benefit from infliximab dose escalation in each study. Thus the clinical and immunological features of these patients who require higher dose of infliximab are not fully understood.

It is tempting to speculate that the production and resultant plasma levels of TNF, the target molecule of infliximab, exceeds the neutralising capacity of infliximab in insufficient responders who are unable to maintain the threshold serum level of infliximab. Considering that hypothesis, we analysed the RISING study data based on plasma TNF levels. We found that the clinical response of patients with high baseline levels of TNF (baseline-TNF) showed a significant improvement with higher doses of infliximab, whereas patients with low baseline-TNF did not have a better response even with higher doses of infliximab.

\section{METHODS}

\section{Patients and study protocol}

The study protocol was approved by the local institutional review board and was carried out in accordance with the Helsinki Declaration and good clinical practice. Patient enrollment criteria and study design have previously been described in detail. ${ }^{16}$ In the RISING study, 327 patients with active RA, despite receiving previous treatment with methotrexate, were administered $3 \mathrm{mg} / \mathrm{kg}$ infliximab at weeks 0,2 and 6 with methotrexate online under the BMJ Journals unlocked scheme, see http:// ard.bmj.com/info/unlocked.dtl 
(open-label period weeks 0-14). Patients were randomly assigned into three groups using a dynamic allocation procedure based on the clinical response at week 10 and were treated with 3 ( $n=99), 6(n=104)$, or $10(n=104) \mathrm{mg} / \mathrm{kg}$ infliximab, every 8 weeks from weeks 14 to 46, with methotrexate (blinded period weeks 14-54).

\section{Laboratory test values and serum infliximab measurement}

Plasma samples for the evaluation of baseline-TNF were collected just before the first infusion of infliximab (week 0). The plasma was separated from EDTA-supplemented blood and was stored at -20 to $-80^{\circ} \mathrm{C}$. Baseline-TNF levels were measured by ELISA using the QantiGlo ELISA Kit (OTA00B; R\&D Systems Inc, Minneapolis, Minnesota, USA) in Mitsubishi Chemical Medience Corporation (Tokyo, Japan). Recombinant human TNF included in the kit was used as reference. Mitsubishi Chemical Medience Corporation has made minor modifications on the assay procedure of the ELISA kit (http://www.rndsystems.com/ pdf/qta00b.pdf) and has validated their detection limit. Since the mean relative light units (2 SD) at blank and $0.55 \mathrm{pg} / \mathrm{ml}$ were 15.2 (3.4) and 25.2 (5.0) by their modified procedure, respectively, the detection limit was determined as $0.55 \mathrm{pg} / \mathrm{ml}$ by adding $2 \mathrm{SD}$ to the relative light units. The coefficient of variation or relative error values of intra-assay or inter-assay TNF were within $3.6 \%$ or $6.2 \%$, respectively. They confirmed that freezing and thawing the plasma sample 10 times and storing at $-20^{\circ} \mathrm{C}$ for 22 weeks did not affect the stability of TNF in the plasma.

Sera were collected at weeks 0 and 2 and every 4 weeks thereafter. The serum infliximab level was measured by ELISA using the anti-infliximab monoclonal antibody obtained from Centocor Ortho Biotech Inc. (Horsham, Pennsylvania, USA). ${ }^{8}$ Serum infliximab levels below $0.1 \mu \mathrm{g} / \mathrm{ml}$ were undetectable.

Baseline rheumatoid factor (RF) was measured by the latex agglutination test. Antibodies against cyclic citrullinated peptides (CCP) and matrix metalloproteinase-3 (MMP-3) levels were measured by ELISA. The detectable ranges were as follows: RF, $3 \mathrm{IU} / \mathrm{ml}$ or greater; anti-CCP antibodies, $0.6 \mathrm{IU} / \mathrm{ml}$ or greater to $100 \mathrm{IU} / \mathrm{ml}$ or less; and MMP-3, $12.5 \mathrm{ng} / \mathrm{ml}$ or greater.

\section{Evaluation of efficacy}

The clinical response to infliximab was evaluated using EULAR criteria, and disease activity was assessed using the disease activity score in 28 joints (DAS28) based on C-reactive protein (CRP) and the ACR core set ${ }^{21}$ at week 54. The EULAR response was evaluated using the DAS28 based on the erythrocyte sedimentation rate (ESR) assessment method (http://www. reuma-nijmegen.nl/www.das-score.nl/index.html). The cut-off values for DAS28-CRP were as follows, based on a report from Inoue et al. ${ }^{22}$ : DAS28-CRP remission, less than 2.3; low disease activity (LDA), 2.3 or greater to less than 2.7; moderate disease activity (MDA), 2.7 or greater to 4.1 or less; high disease activity (HDA), greater than 4.1. Joint damage was assessed by the total modified Sharp score (0-390 points). ${ }^{23}$

\section{Analytical method}

The clinical responses to infliximab at week 54 were analysed for the full analysis set using the last observation carried forward approach. For the comparison of clinical response among dose groups (3, 6 and $10 \mathrm{mg} / \mathrm{kg}$ ), logistic regression analysis was performed using the clinical responses at the time of randomisation (week 10) as a covariate.

Because there is no well-established threshold value for an abnormal TNF level in the ELISA kit used, the detection limit, less than $0.55 \mathrm{pg} / \mathrm{ml}$, and a threefold higher level, $1.65 \mathrm{pg} / \mathrm{ml}$, were adopted as cut-off values, and the patients were stratified into the following three patient groups for analysis: low, less than $0.55 \mathrm{pg} / \mathrm{ml}$ (TNF-low); intermediate, $0.55 \mathrm{pg} / \mathrm{ml}$ or greater to less than $1.65 \mathrm{pg} / \mathrm{ml}$ (TNF-int); and high, $1.65 \mathrm{pg} / \mathrm{ml}$ or greater (TNF-high).

The association of baseline-TNF with baseline disease activity and the efficacy of infliximab therapy was analysed for the three groups described above (TNF-low, TNF-int and TNFhigh patients) employing the Kendall rank correlation coefficient. Baseline disease activity was analysed for the enrolled patients $(\mathrm{n}=327)$. Clinical responses (DAS28-CRP or ACR core set) and efficacy on physical function (improved health assessment questionnaire (HAO) score) at week 54 were analysed using the last observation carried forward approach $(n=307)$. Radiographic progression was analysed in the patients whose radiographic data were obtained at week $54(n=273)$. The association between the serum infliximab level and clinical response or disease activity at week 54 was analysed in the patients for whom both serum levels and DAS28-CRP values were obtained at week $54(\mathrm{n}=271)$.

Primary non-responders were defined as patients who had not achieved LDA throughout the study period (at weeks 2-54), and secondary non-responders as those who had not achieved LDA at week 54 but had achieved it at least once between weeks 2 and 50. Kruskal-Wallis test analysis was performed to compare the rates of TNF-low, TNF-int and TNF-high patients in primary and secondary non-responders versus responders (those who had achieved LDA at week 54).

\section{RESULTS}

\section{Patients' background and association between baseline-TNF and parameters of disease activity at baseline}

Table 1 shows the baseline demographics and clinical characteristics of the enrolled patients $(n=327)$. The median (IOR), minimum and maximum baseline-TNF values were $0.92 \mathrm{pg} / \mathrm{ml}$ $(<0.55-1.29 \mathrm{pg} / \mathrm{ml})$, less than $0.55 \mathrm{pg} / \mathrm{ml}$ and $9.68 \mathrm{pg} / \mathrm{ml}$, respectively. The proportion of patients with baseline-TNF values less than $0.55 \mathrm{pg} / \mathrm{ml}$ (undetectable), $0.55 \mathrm{pg} / \mathrm{ml}$ or greater to less than $1.65 \mathrm{pg} / \mathrm{ml}$, and $1.65 \mathrm{pg} / \mathrm{ml}$ or greater (TNF-low, TNF-int and TNF-high patients) was $28.7 \%, 58.4 \%$ and $12.8 \%$, respectively. Details on the distribution of baseline-TNF can be found in supplementary figure 1 (available online only). Baseline-TNF was significantly, but slightly, correlated with most parameters of disease activity and HAQ score, but not with radiographic progression (table 2). The significant correlations of baseline-TNF with RF and anti-CCP antibodies were also observed.

\section{Clinical response to infliximab at week $\mathbf{5 4}$}

Of the enrolled patients, 307 were treated with 3,6 or $10 \mathrm{mg} / \mathrm{kg}$ infliximab during the blinded period, and clinical response was evaluated at week 54 using DAS28-CRP (figure 1). The clinical responses at week 54 were significantly higher in the $10 \mathrm{mg} / \mathrm{kg}$ group than in the $3 \mathrm{mg} / \mathrm{kg}$ group, and $45.2 \%$ of the patients in the $10 \mathrm{mg} / \mathrm{kg}$ group achieved DAS28-CRP remission.

\section{Association between baseline-TNF and the efficacy of infliximab therapy at week $\mathbf{5 4}$}

The EULAR responses and disease activities at week 54 in TNFlow $(n=87)$, TNF-int $(n=180)$, and TNF-high $(n=40)$ patients are shown in figure $2 \mathrm{~A}, \mathrm{~B}$. In TNF-low patients, the clinical response was similar among the 3,6 and $10 \mathrm{mg} / \mathrm{kg}$ groups, showing no dose dependency. In TNF-int patients, the EULAR 
Table 1 Baseline demographics and clinical characteristics of patients enrolled in the RISING study $(n=327)$

\begin{tabular}{|c|c|}
\hline & Baseline value \\
\hline Age, year & $49.9(12.0)$ \\
\hline Gender, female & $267(81.7)^{*}$ \\
\hline Disease duration, years & $8.2(8.0)$ \\
\hline \multicolumn{2}{|l|}{ Steinbrocker stage } \\
\hline 1 & $32(9.8)^{*}$ \\
\hline ॥ & $114(34.9)^{*}$ \\
\hline III & $105(32.1)^{*}$ \\
\hline IV & $76(23.2)^{*}$ \\
\hline \multicolumn{2}{|l|}{ Steinbrocker functional class } \\
\hline 1 & $58(17.7)^{*}$ \\
\hline 2 & $239(73.1)^{*}$ \\
\hline 3 & $30(9.2)^{*}$ \\
\hline 4 & $0(0.0)^{*}$ \\
\hline Duration of methotrexate use, years & $2.7(2.8)$ \\
\hline Methotrexate dose, mg/week & $7.8(1.7)$ \\
\hline Glucocorticoid use & $223(68.2)^{*}$ \\
\hline DAS28-CRP & $5.5(4.9,6.2)^{\dagger}$ \\
\hline DAS28-ESR & $6.2(5.6,6.8)^{\dagger}$ \\
\hline TJC, 68 joints & $15.0(10.0,23.0)^{\dagger}$ \\
\hline SJC, 66 joints & $12.0(9.0,17.0)^{\dagger}$ \\
\hline CRP, mg/dl & $2.4(1.2,4.1)^{\dagger}$ \\
\hline $\mathrm{ESR}, \mathrm{mm} / \mathrm{h}$ & $52(35,72)^{\dagger}$ \\
\hline Patient pain VAS, mm & $54(39,72)^{\dagger}$ \\
\hline Patient global VAS, mm & $54(36,72)^{\dagger}$ \\
\hline Physician global VAS, mm & $64(50,78)^{\dagger}$ \\
\hline TSS $^{\ddagger}$ & $35.5(11.5,73.4)^{\dagger}$ \\
\hline Estimated yearly progression of TSS, point/year ${ }^{\ddagger}$ & $6.1(3.1,11.4)^{\dagger}$ \\
\hline HAO & $1.1(0.8,1.6)^{\dagger}$ \\
\hline RF value, IU/ml & $90(36,223)^{\dagger}$ \\
\hline Anti-CCP antibodies value, IU/ml & $\geq 100(28, \geq 100)^{\dagger}$ \\
\hline MMP-3 value, $\mathrm{ng} / \mathrm{ml}$ & $219(105,419)^{\dagger}$ \\
\hline
\end{tabular}

\footnotetext{
Data in baseline values are mean (SD), ${ }^{*}$ number of patients (\%), or ${ }^{\dagger}$ median (IQR).

Health assessment questionnaire (HAQ) score: scores can range from 0 (no difficulty) to 3 (unable to perform this activity).

Total modified Sharp score (TSS): scores can range from 0 to 390 (erosion score 0-230, joint space narrowing score $0-160)$, with high scores indicating more joint damage. Estimated yearly rate of progression of the TSS was based on the duration of disease and baseline TSS for every patient.

${ }^{\ddagger} \mathrm{n}=325$.

CCP, cyclic citrullinated peptide; CRP, C-reactive protein; DAS 28, disease activity score in 28 joints; ESR, erythrocyte sedimentation rate; MMP-3, matrix metalloproteinase 3:

$\mathrm{RF}$, rheumatoid factor; SJC, swollen joint count; TJC, tender joint count; VAS, visual analogue scale.
}

response rate increased and disease activity decreased as the dose increased, but without significant difference. For TNFhigh patients, the clinical response and disease activity were significantly better at $10 \mathrm{mg} / \mathrm{kg}$ than at $3 \mathrm{mg} / \mathrm{kg}$ and $6 \mathrm{mg} / \mathrm{kg}$. The good response rates were $14 \%, 31 \%$ and $60 \%$ in the 3,6 and $10 \mathrm{mg} / \mathrm{kg}$ groups, respectively, and the DAS28-CRP remission rates were $7 \%, 31 \%$ and $50 \%$, respectively. A similar influence by baseline-TNF was also noted on the ACR core set (figure 2C). Significant dose dependency was observed only in TNF-high patients.

Baseline-TNF at clinical response is shown in supplementary table 1 (available online only). Clinical response was significantly influenced by baseline-TNF in the $3 \mathrm{mg} / \mathrm{kg}$ group, but not in the 6 and $10 \mathrm{mg} / \mathrm{kg}$ groups. Baseline-TNF also influenced the improving physical function, in which the improvement in the HAQ score values and the rates of patients with meaningful improvement $(>0.22)$ in all dosage groups were significantly different in TNF-high patients (supplementary table 2, available online only). Meanwhile, none of the groups showed significant association with radiographic progression.

The proportions of TNF-low, TNF-int and TNF-high patients in responders $(n=148)$ were $34.5 \%, 56.8 \%$ and $8.8 \%$, respectively.
On the other hand, those of primary non-responders $(n=88)$ were $21.6 \%, 62.5 \%$ and $15.9 \%$, and those of secondary nonresponders $(n=71)$ were $23.9 \%, 57.7 \%$ and $18.3 \%$, respectively. Significant differences were observed between the responders and both of the non-responders $(p=0.016$ and $p=0.032$, respectively).

\section{Association between baseline-TNF and serum infliximab level}

Clinical response to infliximab has been shown to be influenced by trough serum infliximab levels, and the threshold level for clinical response is approximately $1 \mu \mathrm{g} / \mathrm{ml} .{ }^{20}{ }^{24}$ In this study, the median (IOR) serum infliximab level at week 54 in patients with EULAR good response, moderate response and no response was $3.1(1.2-7.1), 1.2(<0.1-3.6)$ and less than 0.1 $(<0.1-0.4) \mu \mathrm{g} / \mathrm{ml}$. The median (IOR) level in patients in DAS28CRP remission, with $\mathrm{LDA}$, with MDA and with $\mathrm{HDA}$ at week 54 was 3.4 (1.5-7.5), $2.1(0.4-4.7), 1.4(<0.1-4.0)$ and less than $0.1(<0.1-0.7) \mu \mathrm{g} / \mathrm{ml}$, respectively. A significant association was observed between clinical response or disease activity and the serum infliximab level (both $\mathrm{p}<0.001$ ). In patients with high trough serum infliximab levels, better clinical responses were attained. Meanwhile, in patients with poor clinical response (EULAR no response, high disease activity), the median trough serum level was undetectable $(<0.1 \mu \mathrm{g} / \mathrm{ml})$.

Baseline-TNF greatly affected the serum infliximab levels (figure $3 \mathrm{~A}-\mathrm{C}$ ). In TNF-low patients, the median trough serum infliximab levels were equivalent to or greater than the threshold level $(1 \mu \mathrm{g} / \mathrm{ml})$ in all groups (3, 6 and $10 \mathrm{mg} / \mathrm{kg})$. For TNF-int patients, the $3 \mathrm{mg} / \mathrm{kg}$ dose did not achieve the threshold level of infliximab but did provide a detectable level $(\geq 0.1 \mu \mathrm{g} / \mathrm{ml})$. However, in TNF-high patients, the median trough serum infliximab levels were undetectable at both 3 and $6 \mathrm{mg} / \mathrm{kg}$ doses, in contrast to the $10 \mathrm{mg} / \mathrm{kg}$ dose, at which a high level $(>2 \mu \mathrm{g} / \mathrm{ml})$ was maintained.

The positive rates for anti-infliximab antibodies (human antichimeric antibodies; HACA), which is reported to influence the serum infliximab level ${ }^{25}$ were $27.3 \%, 23.1 \%$ and $12.5 \%$ in the 3 , 6 and $10 \mathrm{mg} / \mathrm{kg}$ dose levels, respectively. In patients who were negative for HACA, the serum infliximab level was also lower in TNF-high patients than in TNF-low patients, and the median serum infliximab levels at the $3 \mathrm{mg} / \mathrm{kg}$ dose at week 54 in TNFlow patients $(n=23)$, TNF-int patients $(n=37)$ and TNF-high patients $(\mathrm{n}=8)$ were $1.0,0.6$ and $0.2 \mu \mathrm{g} / \mathrm{ml}$, respectively.

\section{Association between safety and baseline-TNF or serum infliximab level}

The incidences of adverse events (total, serious events, infection, serious infection, or infusion reaction) were almost comparable among patients receiving 3, 6 and $10 \mathrm{mg} / \mathrm{kg}$ doses in TNF-low, TNF-int and TNF-high patients. We could find no clear association between the incidence of adverse events and the trough serum level of infliximab either (supplementary table 3, available online only).

\section{DISCUSSION}

Although dose escalation or shortening of the administration interval between administrations has been used for patients with RA who show an insufficient response to the standard dose of infliximab ( $3 \mathrm{mg} / \mathrm{kg}$ for 8 weeks after initial induction), the effectiveness of these countermeasures is still controversial. ${ }^{18-20} 26-32$ In this report, we hypothesised that the production and resultant plasma level of TNF exceeds the neutralising capacity of infliximab in insufficient responders; and that infliximab is consumed 
Table 2 Baseline disease activities in TNF-low, TNF-int and TNF-high patients

\begin{tabular}{|c|c|c|c|c|}
\hline & \multicolumn{3}{|c|}{ Baseline-TNF } & \multirow[b]{2}{*}{ p Value (overall) } \\
\hline & TNF-Iow (n=94) & TNF-int (n=191) & TNF-high $(n=42)$ & \\
\hline DAS28-CRP & $5.3(4.9,5.9)$ & $5.5(5.0,6.2)$ & $5.9(5.2,6.7)$ & 0.002 \\
\hline DAS28-ESR & $5.9(5.5,6.4)$ & $6.2(5.7,6.8)$ & $6.8(6.2,7.3)$ & $<0.001$ \\
\hline SJC, 66 joints & $11.0(8.0,16.0)$ & $13.0(9.0,17.0)$ & $12.5(10.0,18.0)$ & 0.041 \\
\hline Patient pain VAS, mm & $49.0(37.0,65.0)$ & $58.0(40.0,72.0)$ & $68.5(46.0,88.0)$ & $<0.001$ \\
\hline Patient global VAS, mm & $51.0(36.0,64.0)$ & $56.0(36.0,72.0)$ & $65.0(43.0,86.0)$ & 0.016 \\
\hline ESR $(\mathrm{mm} / \mathrm{h})$ & $46.0(33.0,65.0)$ & $53.0(35.0,72.0)$ & $67.5(40.0,89.0)$ & 0.001 \\
\hline $\mathrm{HAO}$ & $1.0(0.5,1.4)$ & $1.1(0.9,1.6)$ & $1.4(1.0,2.1)$ & 0.002 \\
\hline TSS & $37.0(10.5,76.0)^{*}$ & $36.0(12.5,72.3)^{\dagger}$ & $22.5(13.0,56.0)$ & 0.960 \\
\hline Estimated yearly progression of TSS, point/year & $5.8(2.8,12.0)^{*}$ & $6.3(3.4,11.3)^{\dagger}$ & $5.5(2.5,10.0)$ & 0.833 \\
\hline $\mathrm{RF}$ value, IU/ml & $85(27,215)$ & $81(37,167)$ & $238(126,554)$ & 0.007 \\
\hline Anti-CCP antibodies value, IU/ml & $91(17, \geq 100)$ & $\geq 100(30, \geq 100)$ & $\geq 100(\geq 100, \geq 100)$ & 0.012 \\
\hline
\end{tabular}

\footnotetext{
Data in baseline value are median (IQR).
}

Baseline disease activities were evaluated in the patients enrolled in the RISING study ( $n=327)$. The associations of baseline-tumour necrosis factor alpha (TNF) with baseline disease activities were analysed in the three groups (TNF-low, TNF-int and TNF-high patients) employing the Kendall rank correlation coefficient. ${ }^{*} \mathrm{n}=93$.

${ }^{\dagger} \mathrm{n}=190$.

CCP, cyclic citrullinated peptide; CRP, C-reactive protein; DAS28, disease activity score in 28 joints; ESR, erythrocyte sedimentation rate; HAQ, health assessment questionnaire; MMP-3, matrix metalloproteinase 3; RF, rheumatoid factor; SJC, swollen joint count; TJC, tender joint count; TSS, total modified Sharp score; VAS, visual analogue scale.

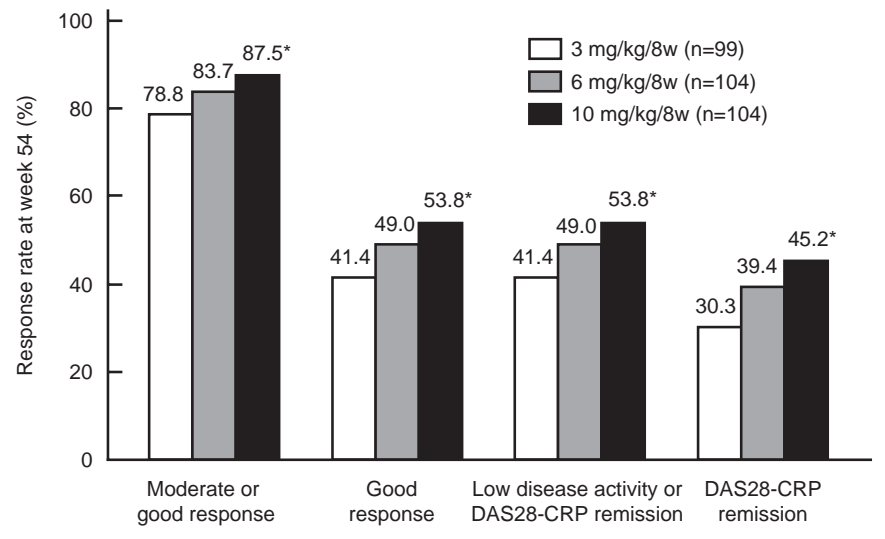

Figure 1 Clinical responses to infliximab therapy in patients with rheumatoid arthritis at week 54. The European League Against Rheumatism response criteria and disease activity were measured by the disease activity score in 28 joints (DAS28)-C-reactive protein (CRP) using the last observation carried forward method. Disease activity was defined as high disease activity, DAS28-CRP greater than 4.1; moderate disease activity, 2.7 or greater to 4.1 or less; low disease activity, 2.3 or greater to less than 2.7; and DAS28-CRP remission, less than 2.3. ${ }^{*} \mathrm{p}<0.05$ versus the $3 \mathrm{mg} / \mathrm{kg}$ groups.

to neutralise the TNF, decreasing the serum infliximab level in those patients.

In our study, clinical responses at doses of 3,6 and $10 \mathrm{mg} / \mathrm{kg}$ of infliximab were comparable in TNF-low patients, and the minimum serum infliximab level required for clinical response (approximately $1 \mu \mathrm{g} / \mathrm{ml}$ ) was maintained, even in the $3 \mathrm{mg} /$ $\mathrm{kg}$ group. Accordingly, the maximal clinical responses can be achieved even with $3 \mathrm{mg} / \mathrm{kg}$ therapy in TNF-low patients. In other words, dose escalation does not provide any benefit in this population. In contrast, in TNF-high patients, clinical responses at 3 and $6 \mathrm{mg} / \mathrm{kg}$ were significantly decreased in comparison with the response to a $10 \mathrm{mg} / \mathrm{kg}$ dose. The trough serum infliximab levels were 'undetectable' at 3 and $6 \mathrm{mg} /$ $\mathrm{kg}$ but were greater than $2 \mu \mathrm{g} / \mathrm{ml}$ with a $10 \mathrm{mg} / \mathrm{kg}$ dose. As the association between baseline-TNF and the serum infliximab level was also observed in HACA-negative patients, this association was not reflected by the presence of HACA status.

It has been suggested that the threshold serum level for infliximab efficacy on radiographic progression might be lower than that for clinical response. ${ }^{33}$ In this study, approximately $90 \%$ of the patients whose serum level could be maintained over the threshold for radiographic progression, including even TNF-high patients, showed no radiographic progression. It may explain why baseline-TNF status had no influence on radiographic progression as observed in this study.

The present report has demonstrated that higher doses of infliximab exhibited significantly better clinical and functional response in patients with high baseline-TNF, whereas clinical and functional response was comparable among patients administered 3,6 and $10 \mathrm{mg} / \mathrm{kg}$ of infliximab with low baseline-TNF.

We had reported previously that there was no difference in the safety profile among groups receiving 3, 6 or $10 \mathrm{mg} / \mathrm{kg}$. ${ }^{16}$ The rates of adverse events were almost comparable among all dosage groups in TNF-low, TNF-int and TNF-high patients. However, it has been reported that high-dose infliximab therapy might increase the risk of adverse events. ${ }^{11} 3435$ So, the balance between risk and benefit should be considered at the time of infliximab dose escalation, even in TNF-high patients.

There have been several reports on the association between TNF level and the efficacy of infliximab. ${ }^{36-39}$ Although the reason for the inconsistent results is unclear, the serum TNF level was measured by bioassay in the report by Marotte et $a l^{37}$ which is different from this study, in which ELISA was employed. In the studies by Wijbrandts et al, ${ }^{38}$ clinical response was evaluated at week 16, 2 weeks after infliximab administration when a high serum infliximab level may have been maintained even in patients with a high baseline-TNF. These differences may have led to the different conclusions.

In the RISING study, baseline-TNF was measured in one institution (Mitsubishi Chemical Medience Corporation) concurrently, where minor modifications were made in the original assay procedure and validated for the commercial use of clinical samples. 

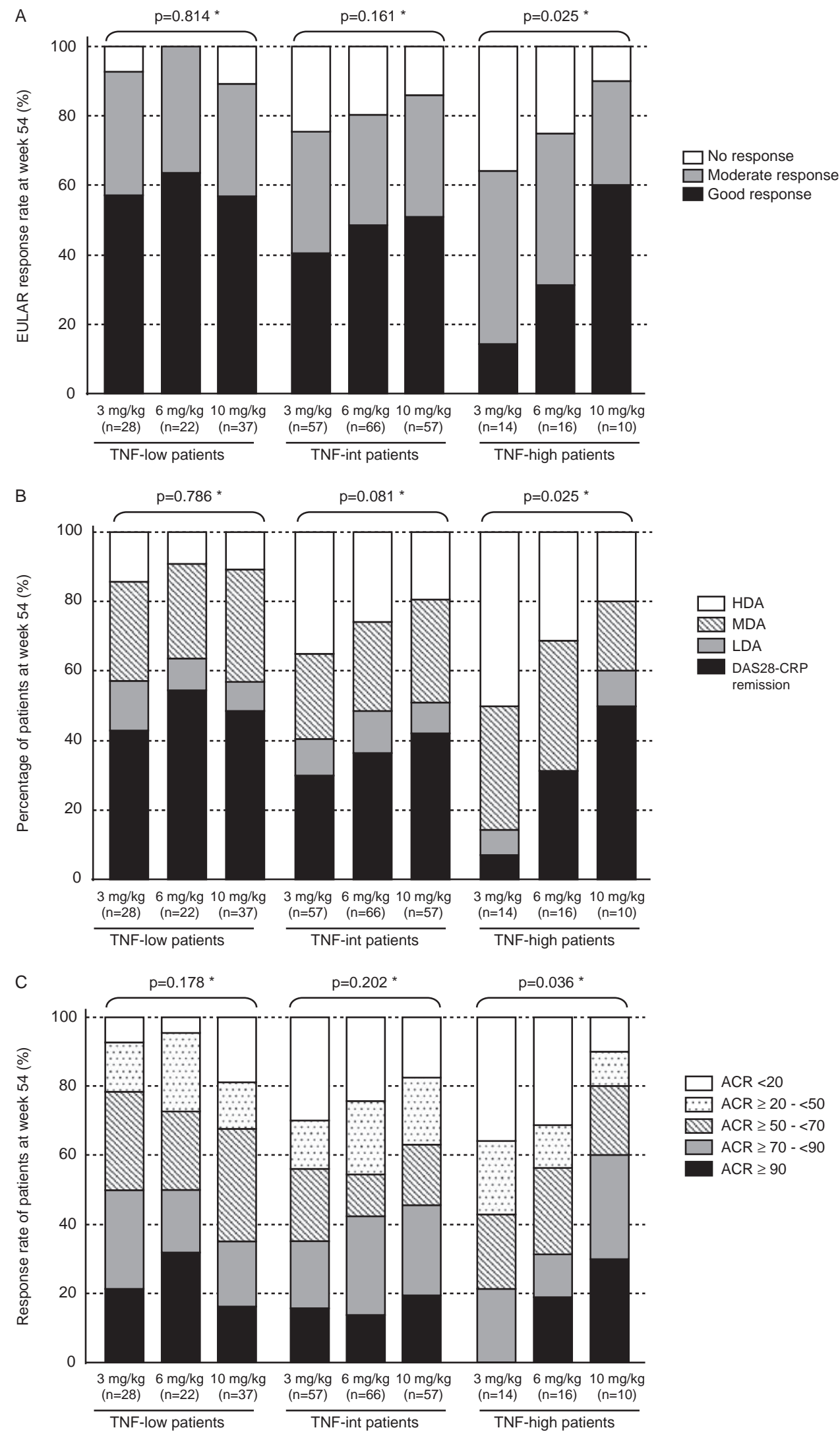

Figure 2 Correlation of plasma tumour necrosis factor alpha (TNF) levels before infliximab therapy (baseline-TNF) with (A) the European League Against Rheumatism (EULAR) response, (B) the disease activity score in 28 joints (DAS28) and (C) American College of Rheumatology (ACR) core set at week 54. Patients were divided into three patients groups by the baseline-TNF level as follows: TNF-low patients, less than $0.55 \mathrm{pg} / \mathrm{ml}$; TNF-int patients, $0.55 \mathrm{pg} / \mathrm{ml}$ or greater to less than $1.65 \mathrm{pg} / \mathrm{ml}$; and TNF-high patients, $1.65 \mathrm{pg} / \mathrm{ml}$ or greater. EULAR response criteria for disease activity were measured by DAS28-C-reactive protein (CRP). Disease activity was defined as high disease activity (HDA), DAS28-CRP greater than 4.1; moderate disease activity (MDA), 2.7 or greater to 4.1 or less; low disease activity (LDA), 2.3 or greater to less than 2.7; and DAS28-CRP remission, less than 2.3. All clinical responses were evaluated by using the last observation carried forward method. *Kendall rank correlation coefficient. 

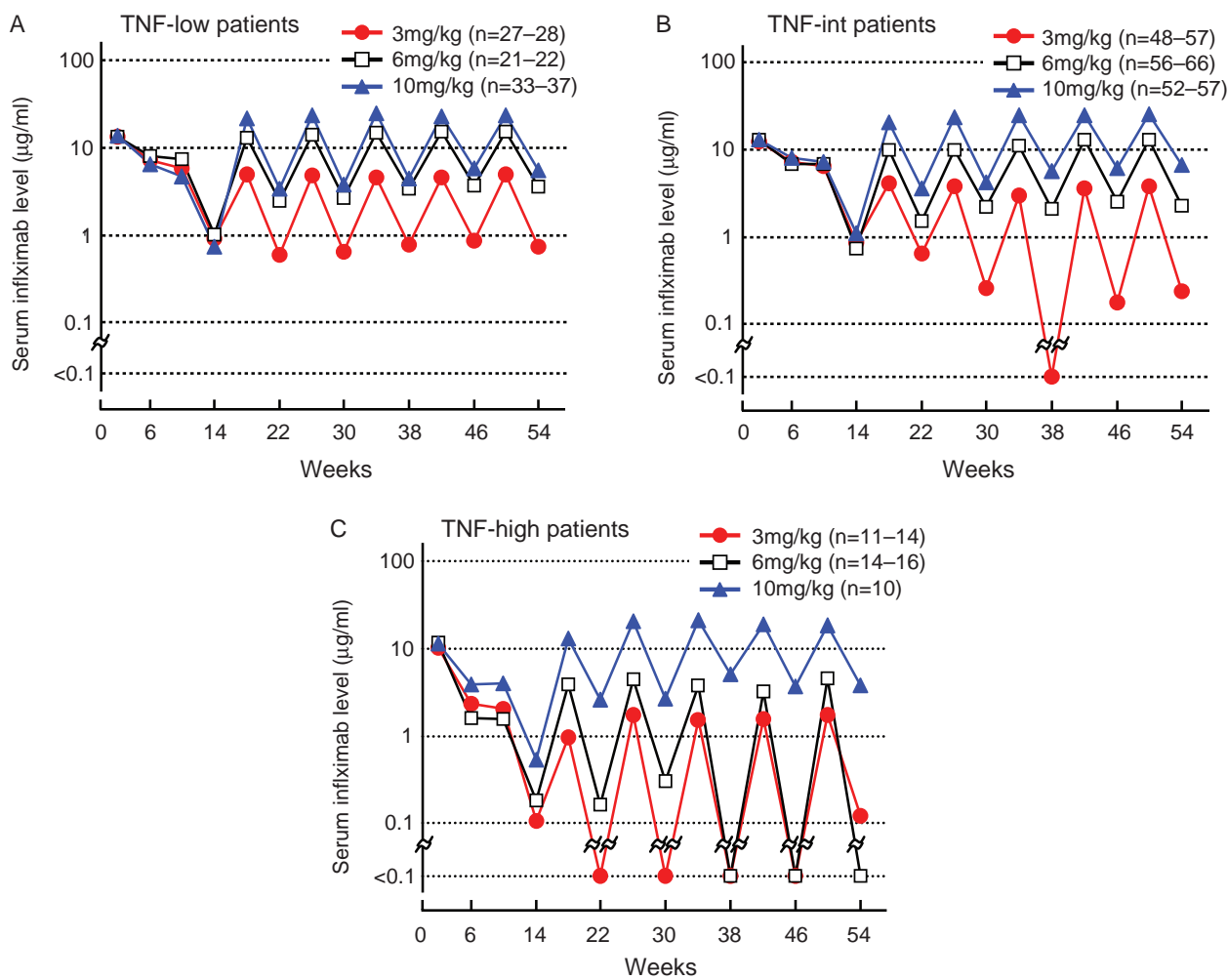

Figure 3 Serum infliximab levels in (A) tumour necrosis factor alpha (TNF)-low, (B) TNF-int and (C) TNF-high patients. Patients were divided into three groups by the plasma TNF level before infliximab therapy (baseline-TNF) as follows: TNF-low patients, less than $0.55 \mathrm{pg} / \mathrm{ml}$; TNF-int patients, $0.55 \mathrm{pg} / \mathrm{ml}$ or greater to less than $1.65 \mathrm{pg} / \mathrm{ml}$; and TNF-high patients, $1.65 \mathrm{pg} / \mathrm{ml}$ or greater. Serum infliximab levels were measured by ELISA.

It was reported that $\mathrm{RF}$ in the samples may cause false-positive results in immunoassays by cross-linking the capture and detection antibodies. ${ }^{40}$ In our study, a significant correlation was observed between TNF and RF at baseline ( $\tau$ value $0.129, p<0.001)$. However, the maximum baseline RF level was $1560 \mathrm{IU} / \mathrm{ml}$ in patients with undetectable baseline-TNF (supplementary figure 2, available online only). Therefore, we considered that RF might interfere with the assay of TNF in patients with greater than $1560 \mathrm{IU} / \mathrm{ml}$, but not in patients with less than $1560 \mathrm{IU} / \mathrm{ml}$. Furthermore, we freshly collected the plasma samples from 39 patients with RA (in which backgrounds were shown in supplementary table 4, available online only), and carried out several tests to evaluate the effects of RF on the ELISA for TNF: 'RF-blocking test', using $40 \%$ mouse serum, $20 \%$ goat serum and $20 \%$ rabbit serum; 41 ' 42 'IgM-RF adding test', using purified polyclonal IgM-RF (Interference Check RF Plus; Sysmex Corporation, Kobe, Japan); 'mismatch simplex sandwich test', ${ }^{42}$ using anti-interleukin 6 antibodies conjugated to horseradish peroxidase from the QantiGlo ELISA Kit for interleukin 6 (Q6000B; R\&D Systems Inc) as the detection antibodies. As we did not find a clear signal indicating that RF interacted with our ELISA for TNF, we considered that the TNF levels in our study were not influenced by RF (supplementary tables $5-7$, available online only).

The circulating TNF level in patients with RA varied from several $\mathrm{pg} / \mathrm{ml}$ to greater than $100 \mathrm{pg} / \mathrm{ml}$ in different reports. ${ }^{43-46}$ Although the patient background should be considered in determining the cause of the variation, the measurement systems used for detecting circulating TNF levels in individual studies may largely account for the variation. In that regard, the cut-off values for baseline-TNF used in this report (0.55 and $1.65 \mathrm{pg} / \mathrm{ml}$ ) were not absolute, and the titre should be standardised in the future.

So far, some of the patient backgrounds have been investigated for predictors of their clinical response to infliximab. Baseline
CRP was reported to be associated with the serum infliximab level, ${ }^{47}$ but no consensus has been obtained about the correlation between baseline CRP and clinical response. ${ }^{36} 48$ We investigated the influence of baseline CRP on the clinical response as an index of EULAR response as done by baseline-TNF. However, we could find no clear relationship between them (supplementary figure $3 \mathrm{~A}, \mathrm{~B}$, available online only). Given that TNF is one of the key cytokines that induce CRP in various inflammatory diseases such as RA, it is reasonable that baseline-TNF, rather than CRP, would be a good predictor of clinical response to the TNF inhibitor, infliximab.

Many contradictory reports have been published regarding the effectiveness of dose escalation with infliximab. ${ }^{18-20}$ 26-32 The reason why no consensus has been reached is that dose escalation is significant only in TNF-high patients, so the results of reports have been influenced by the number of patients with high baseline-TNF included in those studies. In the RISING study, TNF-high patients accounted for approximately $13 \%$ of the total.

This study may provide insight into our understanding of the relationship between the concentration of circulating cytokines and the dose of antibodies against the cytokines in the treatment of RA. As mentioned by van Vollenhoven, ${ }^{26}$ an attempt to apply results obtained under highly controlled circumstances at the group level to the unique individual is necessary. These results may be useful for establishing treatment strategies, such as the appropriate dose of infliximab in accordance with baseline-TNF in patients with RA, not only in daily clinical practice but also in relation to the economics of health care.

Acknowledgements The authors wish to thank all the investigators participated in the RISING study: F. Hirano, K. Taneichi, T. Atsumi, K. Ohnishi, H. Takahashi, Hokkaido; N. Chiba, Iwate; T. Sasaki, Miyagi; K. Chiba, T. Kanno, Fukushima; S. Ohta, T. Sumida, Ibaraki; T. Yoshio, K. Kurasawa, Tochigi; Y. Handa, T. Mimura, Saitama; R. Matsumura, 
N. Nakagawa, N. Watanabe, Chiba; K. Inoue, K. Saigo, M. Takei, T. Suguro, T. Kasama, M. Hirakata, Y. Kuga, A. Nakajima, K. Yamaji, K. Yamamoto, E. Saito, H. Yamagata, M. Tateishi, S. Sawada, N. Kamatani, H. Yamanaka, M. Nakajima, Tokyo; S. Toma, H. Endo, Kanagawa; T. Kuroda, Niigata; S, Honjo, Toyama; I. Koni, M. Kawano, S. Nakazaki, Ishikawa; K. Sugimoto, Fukui; K. Kanzaki, Yamanashi; T. Kanamono, A. Suzuki, Nagano; T. Ohashi, Y. Kusaka, Gifu; H. Ohashi, Y. Izui, N. Ogawa, T. Miyamoto, Shizuoka; N. Ishiguro, Y. Eto, S. Yoshida, Aichi; S. Tamaki, Mie; T. Fujii, M. Tanaka, Kyoto; M. Inaba, T. Koike, Y. Shimaoka, T. Takeuchi, A. Ogata, Y. Saeki, S. Osawa, K. Shi, Osaka; S. Kumagai, T. Nishiyama, H. Sano, T. Matsubara, Hyogo; Y. Murakawa, Shimane; M. Yamamura, K. Ezawa, Okayama; Y. Yamanishi, S. Yamana, Hiroshima; H. Tanaka, Yamaguchi; K. Tani, Tokushima; M. Tokuda, H. Dobashi, M. Inoo, Kagawa; S. Nakata, K. Takasugi, Ehime; I. Furugou, Y. Tanaka, K. Saito, T. Horiuchi, T. Shuto, Y. Nakashima, H. Miyahara, M. Kondo, Fukuoka; K. Eguchi, Y. Ueki, Nagasaki; M. Tsukano, Kumamoto; Y. Fujjkawa, Oita; T. Matsuda, Kagoshima; Y. Shiohira, Okinawa.

Funding Mitsubishi Tanabe Pharma Corporation sponsored this clinical trial and was responsible for the collection and analysis of data. The authors and the sponsor were involved with study design and the interpretation of data. The corresponding author had full access to all the data in the study and had final responsibility for the decision to submit the report for publication.

Competing interests $\mathrm{TT}$ and NM have received research support and consulting or lecture fees from Mitsubishi Tanabe Pharma Corporation. YT, TY and TY are employees of Mitsubishi Tanabe Pharma Corporation. TA and TK have received consulting and lecture fees from Mitsubishi Tanabe Pharma Corporation.

\section{Patient consent Obtained.}

Ethics approval The study protocol was approved by the local institutional review board and was carried out in accordance with the Helsinki Declaration and good clinical practice.

Provenance and peer review Not commissioned; externally peer reviewed.

\section{REFERENCES}

1. Wolfe F, Hawley DJ. The longterm outcomes of rheumatoid arthritis: work disability: a prospective 18 year study of 823 patients. J Rheumatol 1998;25:2108-17.

2. Feldmann M, Maini RN. Discovery of TNF-alpha as a therapeutic target in rheumatoid arthritis: preclinical and clinical studies. Joint Bone Spine 2002;69:12-18.

3. Saxne T, Palladino MA Jr, Heinegård D, et al. Detection of tumor necrosis factor alpha but not tumor necrosis factor beta in rheumatoid arthritis synovial fluid and serum. Arthritis Rheum 1988;31:1041-5.

4. Holt I, Cooper RG, Denton J, et al. Cytokine inter-relationships and their association with disease activity in arthritis. Br J Rheumatol 1992;31:725-33.

5. Tetta C, Camussi G, Modena V, et al. Tumour necrosis factor in serum and synovial fluid of patients with active and severe rheumatoid arthritis. Ann Rheum Dis 1990;49:665-7.

6. Chu CQ, Field M, Feldmann M, et al. Localization of tumor necrosis factor alpha in synovial tissues and at the cartilage-pannus junction in patients with rheumatoid arthritis. Arthritis Rheum 1991;34:1125-32.

7. Espersen GT, Vestergaard M, Ernst E, et al. Tumour necrosis factor alpha and interleukin-2 in plasma from rheumatoid arthritis patients in relation to disease activity. Clin Rheumatol 1991;10:374-6.

8. Maini RN, Breedveld FC, Kalden JR, et al. Therapeutic efficacy of multiple intravenous infusions of anti-tumor necrosis factor alpha monoclonal antibody combined with lowdose weekly methotrexate in rheumatoid arthritis. Arthritis Rheum 1998;41:1552-63.

9. Lipsky PE, van der Heijde DM, St Clair EW, et al. Infliximab and methotrexate in the treatment of rheumatoid arthritis. Anti-Tumor Necrosis Factor Trial in Rheumatoid Arthritis with Concomitant Therapy Study Group. N Engl J Med 2000;343:1594-602.

10. St Clair EW, van der Heiide DM, Smolen JS, et al. Combination of infliximab and methotrexate therapy for early rheumatoid arthritis: a randomized, controlled trial. Arthritis Rheum 2004;50:3432-43.

11. Westhovens R, Yocum D, Han J, et al. The safety of infliximab, combined with background treatments, among patients with rheumatoid arthritis and various comorbidities: a large, randomized, placebo-controlled trial. Arthritis Rheum 2006:54:1075-86.

12. van Vollenhoven RF, Klareskog L. Infliximab dosage and infusion frequency in clinical practice: experiences in the Stockholm biologics registry STURE. Scand J Rheumatol 2007;36:418-23.

13. Kristensen LE, Geborek P, Saxne T. Dose escalation of infliximab therapy in arthritis patients is related to diagnosis and concomitant methotrexate treatment: observational results from the South Swedish Arthritis Treatment Group register. Rheumatology (Oxford) 2009:48:243-5.

14. Yazici Y, Krasnokutsky S, Barnes JP, et al. Changing patterns of tumor necrosis factor inhibitor use in 9074 patients with rheumatoid arthritis. J Rheumatol 2009:36:907-13.

15. Stern R, Wolfe F. Infliximab dose and clinical status: results of 2 studies in 1642 patients with rheumatoid arthritis. J Rheumatol 2004;31:1538-45.

16. Takeuchi T, Miyasaka N, Inoue K, et al. Impact of trough serum level on radiographic and clinical response to infliximab plus methotrexate in patients with rheumatoid arthritis: results from the RISING study. Mod Rheumatol 2009;19:478-87.
17. Abe T, Takeuchi T, Miyasaka N, et al. A multicenter, double-blind, randomized, placebo controlled trial of infliximab combined with low dose methotrexate in Japanese patients with rheumatoid arthritis. J Rheumato/ 2006;33:37-44.

18. Pavelka K, Jarosová K, Suchý D, et al. Increasing the infliximab dose in rheumatoid arthritis patients: a randomised, double blind study failed to confirm its efficacy. Ann Rheum Dis 2009;68:1285-9.

19. van der Bijl AE, Goekoop-Ruiterman YP, de Vries-Bouwstra JK, et al. Infliximab and methotrexate as induction therapy in patients with early rheumatoid arthritis. Arthritis Rheum 2007; 56:2129-34

20. Rahman MU, Strusberg I, Geusens P, et al. Double-blinded infliximab dose escalation in patients with rheumatoid arthritis. Ann Rheum Dis 2007;66:1233-8.

21. Felson DT, Anderson JJ, Boers M, et al. American College of Rheumatology. Preliminary definition of improvement in rheumatoid arthritis. Arthritis Rheum 1995;38:727-35.

22. Inoue E, Yamanaka H, Hara M, et al. Comparison of Disease Activity Score (DAS)28erythrocyte sedimentation rate and DAS28-C-reactive protein threshold values. Ann Rheum Dis 2007:66:407-9.

23. Sharp JT, Lidsky MD, Collins LC, et al. Methods of scoring the progression of radiologic changes in rheumatoid arthritis. Correlation of radiologic, clinical and laboratory abnormalities. Arthritis Rheum 1971;14:706-20.

24. St Clair EW, Wagner CL, Fasanmade AA, et al. The relationship of serum infliximab concentrations to clinical improvement in rheumatoid arthritis: results from ATTRACT, a multicenter, randomized, double-blind, placebo-controlled trial. Arthritis Rheum 2002; 46:1451-9.

25. Svenson M, Geborek P, Saxne T, et al. Monitoring patients treated with anti-TNFalpha biopharmaceuticals: assessing serum infliximab and anti-infliximab antibodies. Rheumatology (Oxford) 2007;46:1828-34

26. van Vollenhoven RF. How to dose infliximab in rheumatoid arthritis: new data on a serious issue. Ann Rheum Dis 2009;68:1237-9.

27. van Vollenhoven RF, Brannemark S, Klareskog L. Dose escalation of infliximab in clinical practice: improvements seen may be explained by a regression-like effect. Ann Rheum Dis 2004;63:426-30.

28. Sidiropoulos $\mathbf{P}$, Bertsias G, Kritikos HD, et al. Infliximab treatment for rheumatoid arthritis, with dose titration based on the Disease Activity Score: dose adjustments are common but not always sufficient to assure sustained benefit. Ann Rheum Dis 2004; 63:144-8.

29. Blom M, Kievit W, Kuper HH, et al. Frequency and effectiveness of dose increase of adalimumab, etanercept, and infliximab in daily clinical practice. Arthritis Care Res (Hoboken) 2010;62:1335-41

30. Durez $\mathbf{P}$, Van den Bosch F, Corluy L, et al. A dose adjustment in patients with rheumatoid arthritis not optimally responding to a standard dose of infliximab of 3 $\mathrm{mg} / \mathrm{kg}$ every 8 weeks can be effective: a Belgian prospective study. Rheumatology (Oxford) 2005;44:465-8.

31. Zintzaras E, Dahabreh IJ, Giannouli S, et al. Infliximab and methotrexate in the treatment of rheumatoid arthritis: a systematic review and meta-analysis of dosage regimens. Clin Ther 2008:30:1939-55.

32. Ariza-Ariza R, Navarro-Sarabia F, Hernández-Cruz B, et al. Dose escalation of the anti-TNF-alpha agents in patients with rheumatoid arthritis. A systematic review. Rheumatology (Oxford) 2007;46:529-32.

33. Smolen JS, Han C, Bala M, et al. Evidence of radiographic benefit of treatment with infliximab plus methotrexate in rheumatoid arthritis patients who had no clinical improvement: a detailed subanalysis of data from the anti-tumor necrosis factor trial in rheumatoid arthritis with concomitant therapy study. Arthritis Rheum 2005; 52:1020-30

34. Bongartz T, Sutton AJ, Sweeting MJ, et al. Anti-TNF antibody therapy in rheumatoid arthritis and the risk of serious infections and malignancies: systematic review and meta-analysis of rare harmful effects in randomized controlled trials. JAMA 2006;295:2275-85.

35. Neven N, Vis M, Voskuyl AE, et al. Adverse events in patients with rheumatoid arthritis treated with infliximab in daily clinical practice. Ann Rheum Dis 2005;64:645-6.

36. Gibbons LJ, Hyrich KL. Biologic therapy for rheumatoid arthritis: clinical efficacy and predictors of response. BioDrugs 2009;23:111-24.

37. Marotte H, Maslinski W, Miossec P. Circulating tumour necrosis factor-alpha bioactivity in rheumatoid arthritis patients treated with infliximab: link to clinical response. Arthritis Res Ther 2005; 7:R149-55.

38. Wijbrandts CA, Dijkgraaf MG, Kraan MC, et al. The clinical response to infliximab in rheumatoid arthritis is in part dependent on pretreatment tumour necrosis factor alpha expression in the synovium. Ann Rheum Dis 2008;67:1139-44.

39. Buch MH, Reece RJ, Quinn MA, et al. The value of synovial cytokine expression in predicting the clinical response to TNF antagonist therapy (infliximab). Rheumatology (Oxford) 2008:47:1469-75

40. de Jager W, Rijkers GT. Solid-phase and bead-based cytokine immunoassay: a comparison. Methods 2006;38:294-303.

41. Raza K, Falciani F, Curnow SJ, et al. Early rheumatoid arthritis is characterized by a distinct and transient synovial fluid cytokine profile of T cell and stromal cell origin. Arthritis Res Ther 2005; 7:R784-95

42. Kokkonen H, Söderström I, Rocklöv J, et al. Up-regulation of cytokines and chemokines predates the onset of rheumatoid arthritis. Arthritis Rheum 2010:62:383-91. 
43. Petrovic-Rackov L, Pejnovic N. Clinical significance of IL-18, IL-15, IL-12 and TNFalpha measurement in rheumatoid arthritis. Clin Rheumatol 2006;25:448-52.

44. Klimiuk PA, Sierakowski S, Latosiewicz R, et al. Serum cytokines in different histological variants of rheumatoid arthritis. J Rheumatol 2001;28:1211-17.

45. Beckham JC, Caldwell DS, Peterson BL, et al. Disease severity in rheumatoid arthritis: relationships of plasma tumor necrosis factor-alpha, soluble interleukin 2-receptor, soluble CD4/CD8 ratio, neopterin, and fibrin D-dimer to traditional severity and functional measures. J Clin Immunol 1992;12:353-61.

46. Keyszer G, Lambiri I, Nagel R, et al. Circulating levels of matrix metalloproteinases MMP-3 and MMP-1, tissue inhibitor of metalloproteinases 1 (TIMP-1), and MMP-1/
TIMP-1 complex in rheumatic disease. Correlation with clinical activity of rheumatoid arthritis versus other surrogate markers. J Rheumatol 1999;26:251-8.

47. Wolbink GJ, Voskuyl AE, Lems WF, et al. Relationship between serum trough infliximab levels, pretreatment $C$ reactive protein levels, and clinical response to infliximab treatment in patients with rheumatoid arthritis. Ann Rheum Dis 2005;64:704-7.

48. Buch MH, Seto Y, Bingham SJ, et al. C-reactive protein as a predictor of infliximab treatment outcome in patients with rheumatoid arthritis: defining subtypes of nonresponse and subsequent response to etanercept. Arthritis Rheum 2005:52:42-8. 